\title{
Common Good or Self-interest: Influence of Ethical Climate on Teachers' Performance
}

\author{
Michael Jarito Froilan \\ Laoang, Northern Samar, Philippines \\ michael.froilan@deped.gov.ph
}

\section{ABSTRACT}

Teachers are at times caught between performing task for the common good and to serve personal interest. This mixed method concurrent triangulation study delved into the influence of ethical climate on teachers' job performance. Complete enumeration of the 30 respondentteachers who have been working at Laoang National High School, Laoang, Northern Samar for at least one full school year were involved. Ethical Climate Questionnaire (Victor and Cullen, 1988) and teachers' Individual Performance Competency Rating Form (IPCRF) from the previous four school years were utilized to gather quantitative data while in-depth semistructured interview and observation were used to collect qualitative data. Descriptive Statistics, Multiple Regression Analysis, and Thematic Analysis (Clarke and Braun, 2014) were utilized to analyze the data. Teachers' responses exhibited that academic freedom, no solicitation policy, and individualistic decision-making defined principle-based ethical climate; technical assistance, community involvement, and moral support characterized benevolent ethical climate; while career advancement and defend comfort zone described egoist ethical climate. Further, regression analysis revealed that principle-based ethical climate had significant negative influence on teachers' performance. It is recommended that same study be replicated on expanded breadth to reassure its findings.

Key words: Ethical climate, job performance, mixed method concurrent triangulation design, teachers

\section{Corresponding Author: Michael Jarito Froilan}

\section{INTRODUCTION}

Expected to behave in accordance with ethical standards, teachers, just like other professionals, are constantly caught between catering to their personal needs and responding to the well-being of the school as a whole. Certain teachers have been displaying deviant behaviors which, Appelbaum, Iaconi, and Matousek [1] postulated, are caused by conflicting perception mediated by deviant role models supported by the organization. More recently, research investigated the influence of ethics on organizational climate and employee behavior [2].

According to Deigh [3], ethics is a study of what are good and bad ends to pursue in life and what it is right and wrong to do in the conduct of life. One of the well-known theories of moral development is that of Kohlberg [4] who articulated that individuals use different types of ethical criteria and display different types of moral reasoning. He [4] defined three major types of ethical standards, namely, self-interest, caring, and principle.

Norms and values in the workplace are primary determinant of ethical decisions [5] thus teachers' actuations are mere adaptation to the school climate. Reichers and Schneider [6] defined organizational climate as the "shared perception of the way things are around here." Schneider [7] 
averred that climate is psychologically meaningful moral descriptions that people can agree which characterize a system's practices and procedures.

In the context of ethics, Victor \& Cullen [8] first proposed ethical climate theory. According to them [8], ethical climate of an organization refers to the behaviors that are perceived to be ethically correct and how issues regarding deviations away from those expected behaviors are handled in the organization. Maximizing one's own self-interests, maximizing joint interests, or adherence to universal principles are the three distinctions of ethical climate [8]. Whenever teachers conferred for a meeting, variations in their viewpoints regarding salient issues concerning the school are prevalent. Studies have shown that indeed, every person's ethical standards are distinct and relatively incompatible from that of others [9]-[10].

Researchers linked ethical climate directly to the positive behaviors of employees and also to a range of negative work behaviors including tardiness, absenteeism, and social loafing [11]-[12]. Reflective of this, Moore and Moore [2] discovered in their study involving higher education teachers that those faculty members who perceived their institution's ethical climate to be egoistic possess the stance that their school is operating on self-interest, company profit, and efficiency. These negative behaviors have negative ramifications on the behavior of affected individuals [13] or the whole school operations and stakeholders. Poor performance reflected in decreased job satisfaction and organizational commitment, decreased productivity, lower levels of creativity, prolonged antisocial behavior, and escalated employee turnover are amongst the products of negative work behaviors [14], [11]-[12]. Likewise, Fu and Deshpande [15] postulated that moral hazards draping from unethical behavior have impact on normal operations of an institution.

With this, the researcher felt the need to delve into the influence of school's ethical climate [8] categorized into principle-based, benevolent, and egoist ethical climate on teachers' job performance. Findings could be basis for paradigm shift in appraising ethical aspect of various situations within the school as well as guidepost for further studies on the subject with an expounded scope.

\section{MATERIALS AND METHODS}

Mixed method concurrent triangulation research design [16] was used in this study since quantitative and qualitative data were simultaneously gathered and analyzed the results of which were merged to form a cohesive and comprehensive picture of the real conditions. There was a complete enumeration of the 30 teachers from Laoang National High School of Department of Education (DepEd) Northern Samar Division all of whom had been teaching in the school for at least one school year. Instruments used to gather quantitative data included Ethical Climate Questionnaire developed by Victor and Cullen [8] which underwent the usual reliability and validity test and teachers' Individual Performance Competency Rating Form (IPCRF) from school year 2013 - 2014 to 2016 - 2017. In-depth semi-structured interviews were repeatedly conducted until data saturation was achieved covering nine teacher-informants. Being a teacher of the same school, the researcher counter checked their responses through overt participant observation. Appropriate statistical tools such as Descriptive Statistics, Pearson r, and Multiple Regression Analysis were utilized to interpret and analyze quantitative data while the interview transcripts were subjected to thematic analysis through Clarke and Braun's Model [17].

In order to achieve trustworthiness of the qualitative results, appropriate processes were thoroughly followed to meet high degree of credibility, dependability, confirmability, and transferability. Member checking [16], [18] was done by returning the interview transcripts with corresponding codes and themes to the informants for evaluation and confirmation. A colleague, Division Research Coordinator, and a university professor comprised the language experts who scrutinized and made necessary revisions of the codes and themes being formulated.

Moreover, ethical considerations were addressed by providing the respondents and the informants with proper consent form and keeping the confidentiality of their responses which were 
done on voluntary basis. They were neither given any token nor coerced. Sample responses were provided without dropping names. No identifying data was solicited while the whole study posed no physical, psychological, emotional, and financial risks to all of them. Equally important to note, no fabrication or alteration of data was made.

\section{RESULTS AND DISCUSSION}

Table 1 exhibits the school's ethical climate according to the teacher-respondents.

Table 1. Ethical Climate

\begin{tabular}{|c|c|c|c|c|c|}
\hline Ethical climate & $\mathbf{N}$ & Percentage & Mean & Std. Deviation & Interpretation \\
\hline Egoist & 7 & $23.33 \%$ & 3.93 & 0.74 & Prevalent \\
\hline Benevolent & 11 & $36.67 \%$ & 4.06 & 0.21 & Prevalent \\
\hline Principle-based & 12 & $40 \%$ & 4.08 & 0.32 & Prevalent \\
\hline
\end{tabular}

Principle-based ethical climate. The table revealed that more than third of the teachers $(N=$ $12, P=40 \%)$ judged the ethical climate in the school as principle-based $(M=4.06, S D=0.32)$ interpreted as "prevalent." This jibes with the finding of Putranta and Kingshott [19] that principlebased climate was reported as the most dominant climate. It suggests that this cluster of teachers have witnessed co-teachers who hinged their decision making and behavior largely on how they interpret DepEd rules and policies, laws of the land, and performance standards. This is substantiated by predominant themes which include academic freedom, no solicitation policy, and individualistic decision making as shown in Figure 1.

Reflective of this, a teacher shared, "During monthly celebrations, teachers perform their task without being told or monitored." In the same manner, their colleagues submit monthly reports, daily lesson, and hold classes among others primarily because it is stipulated in the rules and responsibilities of teachers thus believed that it is the right thing to do. Whereas, "classroom management," another teacher averred, "is dependent on teacher's personal assessment of the situation." Parboteeah, Praveen Parboteeah, and Kapp [20] supported this by arguing that with principled-individual norms, values, and expectations, people rely on their personal morality when deciding and these had ethical consequences. This concurs with Kohlberg [21] who articulated that in principled stage, personal ethics or self-chosen ethical principles appeal to logical comprehensiveness, universality, and consistency. He [21] added that by utilizing their own judgements concerning personal ethics, members of the group reached a higher level of ethical maturity. In support, Giacalone and Jurkiewicz [22] concluded that principled climate is an extension of Kantian theories wherein morality is a product of analysing the act instead of its consequences.

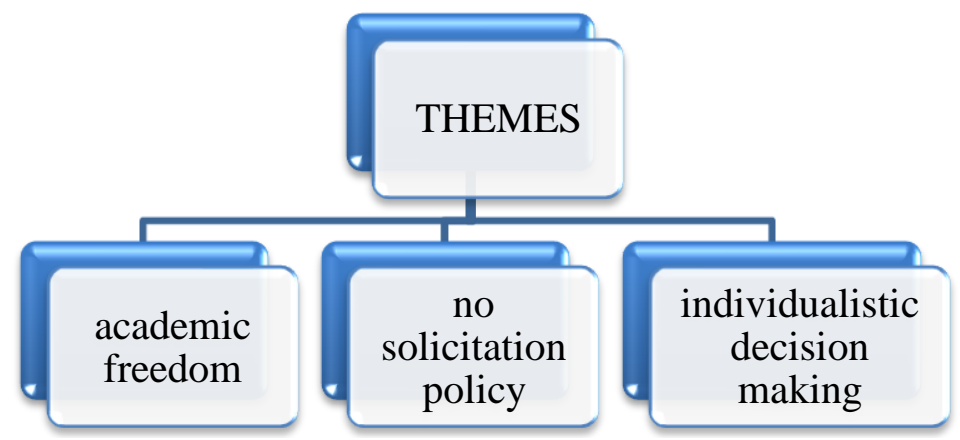

Figure 1. Principled-based climate

Benevolent ethical climate. It can be gleaned on the same table that a third of LNHS teachers $(N=11, P=36.67 \%)$ assessed the school's ethical climate as benevolent $(M=4.06, S D=$ $0.21)$ interpreted as "prevalent" suggesting that they experienced a kind of ethical climate wherein 
colleagues, during decision making, sought for alternative solutions to certain problems that maximizes shared interests of the whole teaching staff even if the decision costs them downgraded satisfaction of personal needs. As Parboteeah et al., [20] pointed out, benevolent climate provides greater good for the greatest number of people. However, unlike utilitarian, benevolent teachers make the sacrifice with utmost sincerity and without prejudice to the recipient of the action [20]. In corroboration to this quantitative finding, Figure 2 presents the most notable benevolent actions as revealed from the interview which included technical assistance, community involvement, and moral support.

To substantiate this, a teacher argued, "In case of absence, another teacher takes charge of the class activities." Someone added, "A colleague enrolled my students in the Learner's Information System without asking money for internet load nor any other forms of favour." In addition, a teacher stipulated that, "I share innovative strategies in classroom supervision without inhibitions." Likewise, "Someone lets her money be borrowed by a colleague who was in need without monthly interest." Whenever LAWAG festival arrives, the teaching staff donates sums of money or the so called, "pass the bag," to raise fund for the snacks and meals of LAWAG dancers, drummers, and props men."

As per observation, some teachers usually sought the assistance of the school's ICT Coordinator in enrolling learners in the Learner's Information System (LIS) and creating a functional gradesheet in MS Excel wherein scores were just inputted and the final grades as well as their corresponding descriptions were automatically displayed. In like manner, Upchurch and Ruhland [23] found that benevolence was the dominant ethical climate dimension.

Supportive of these findings, Giacalone and Jurkiewicz [22] postulated that benevolent climate expedite the development of sense-of-community. They [22] further enunciated that this type of climate leads to mutual caring for one another which strengthens connection and relationship among people. Simha and Stachowicz-Stanusch [24] strongly suggested that organizations should establish benevolent ehtical climate rather than egoist climate.

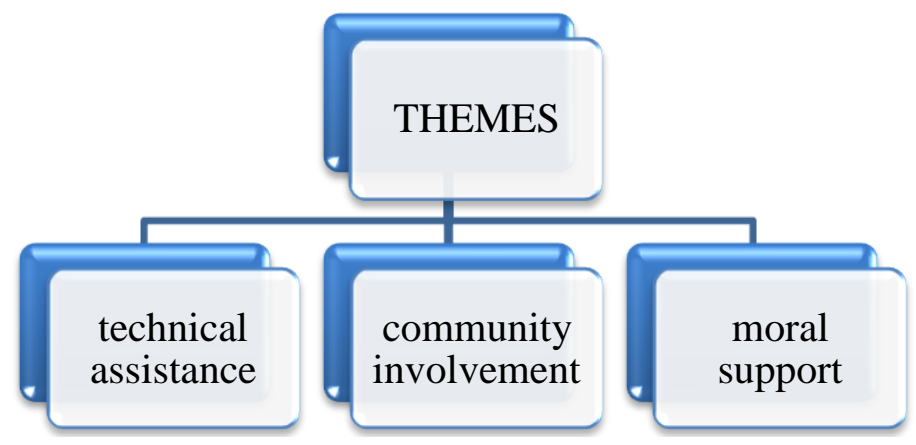

Figure 2. Benevolent climate

Egoist ethical climate. As shown in the same table, a quarter of LNHS teachers $(N=7, P=$ $23.33 \%)$ appraised the ethical climate of the school as egoist $(\mathrm{M}=3.93, \mathrm{SD}=0.74)$ interpreted as "prevalent." This group of teachers observed behavior that prioritizes self-interest. This runs parallel with Ferrell, Fraedrich, and Ferrell [25], Lewin and Lavery [26], and Shaw [27] who stipulated that self-interest can take the form of pleasure, physical well-being, knowledge, a good family life, and wealth or power. In congruence with this finding, Figure 3 shows responses of this group of teachers revealing two themes; career advancement and defend comfort zone.

True enough, a teacher complained, "Why would I do that? Where is my special order." Another teacher stated that, "After earning merits for promotion for assuming as the class adviser of a pilot section, he relinquished the post of committee chairperson." In another instance, a teacher corroborated this by arguing that, "His refusal to handle subjects within his field of specialization is due to absence of special order." This reflected Arnold, Beauchamp, Bowie, and Bowie's [28] 
ethical egoism wherein the person pursue things that would improve his/her own well-being above everyone else's.

On the other hand, Shaw [27] articulated that psychological egoists indulge in activities that appear to promote the welfare of other people, but actually do so to satisfy personal gains. Indicative of this, a teacher calmly shared, "We used to conduct feeding during the monthly celebration of which their subject department was in-charge. But after getting promoted, she repelled even the idea of doing it." When self-interest is at the forefront of ethical climate, employees tend to get dissatisfied [29] hence become less productive.

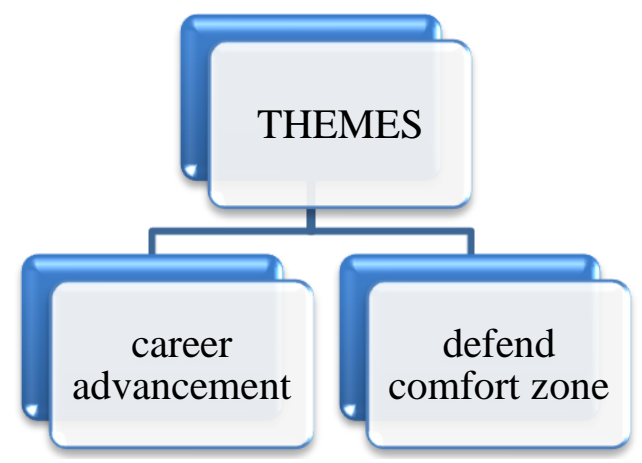

Figure 3. Egoist climate

\section{Test of Relationship between ethical climate constructs and teachers' performance}

Pearson $r$ was utilized to test the relationship between ethical climate constructs and teachers' performance. Table 2.4 indicated that only principle-based climate had significant negative relationship with teachers' performance $(r=-0.409, p<.05)$. This suggests that principle-based ethical climate is inversely related with teachers' performance. This was in contrast with the findings of Yener, Yaldıran, and Ergun [30] wherein social responsibility climate was associated with work engagement. Furthermore, Karatepe [31] discovered that job embeddedness mediated ethical climate and job performance.

Table 2.1. Test of Relationship between ethical climate constructs and teachers' performance

\begin{tabular}{|l|l|c|c|c|}
\hline & & Egoist & Benevolent & Principle-based \\
\hline \multirow{3}{*}{ Teachers' Performance } & Pearson Correlation & .114 & -.141 & $\mathbf{- . 4 0 9}$ \\
\cline { 2 - 5 } & Sig. (2-tailed) & .548 & .457 & $\mathbf{. 0 2 5}$ \\
\cline { 2 - 5 } & Interpretation & Not Significant & Not Significant & Significant \\
\hline
\end{tabular}

*. Correlation is significant at the 0.05 level (2-tailed).

\section{Regression Analysis on the influence of principle-based ethical climate on teachers' performance}

Simple regression analysis was utilized to test the effect of principle-based ethical climate on teachers' performance. The data in table 2.5 showed that, in general, teachers' performance was explained by principle-based climate $16.70 \%$ of the time. Specifically, it revealed that principlebased climate established a negative effect on teachers' performance $(B=-.088, \beta=-0.409, t=-$ $2.372, p<.05)$. This suggests that the more principled ethical climate is, the less productive teachers they become. Reflective of this, in principled climate, people rely too much on their personal analysis of the situation and then act accordingly (Kolhberg, 1984) [21]. Substantiating this concept, Giacalone and Jurkiewicz [22] concluded that principled climate is an extension of Kantian theories wherein morality is a product of analysing the act instead of its consequences. So, when there is a wrong appreciation of the goodness or badness of an action, most likely the decision being chosen leads to poor performance. Putting this into perspective, a teacher stipulated that, 
"One teacher solely decided on the activities to be undertaken for the celebration of the Buwan ng Wika" while another teacher exclaimed, "A teacher in English refused to participate because another teacher made decisions on his own which he thought was right but turned out to lead to unsuccessful activity." These exhibited the assertion of Parboteeah et al., [20] that the principledindividual norms, values, and expectations that people rely on when deciding as the fabrics of their personal morality have ethical consequences. Suffice to say that those ethical consequences could either result to productive or unproductive performance.

Table 2.2. Regression Analysis on the effect of principle-based climate on teachers' performance

\begin{tabular}{|c|c|c|c|c|c|c|}
\hline \multirow{2}{*}{ Model } & \multicolumn{5}{|c|}{ Principle-based ethical climate } \\
\cline { 2 - 7 } & $\mathrm{B}$ & Beta & Std. Error & $\mathrm{t}$ & Sig. & Interpretation \\
\hline \multirow{2}{*}{ Teachers' Performance } & -.088 & -0.409 & 0.037 & \multirow{2}{*}{-2.372} & 0.025 & Strong negative effect \\
\cline { 2 - 8 } & $R=0.409$ & $R^{2}=0.167$ & $F=5.627$ & & & \\
\hline
\end{tabular}

\section{CONCLUSION}

Principle-based ethical climate, although exhibits teachers' moral maturity, could lead to teachers' poor performance when there is wrong appreciation of the situation at hand. The teaching staff of the school should practice collaborative analysis of the goodness and badness of certain decisions so that better outcomes which are reflected in their performance are guaranteed.

\section{REFERENCE}

I. Appelbaum, S. H., Iaconi, G. D., \& Matousek, A. (2007). Positive and negative deviant workplace behaviors: causes, impacts, and solutions. Corporate Governance: The International Journal of Business in Society, 7(5), 586-598.

II. Moore, H. L. \& Moore, T. W. (2014). The effect of ethical climate on the organizational commitment of faculty members. Journal of Academic and Business Ethics, 9, 1-3.

III. Deigh, J. (2009). An Introduction to Ethics. Cambridge University Press.

IV. Kohlberg, L. (1981) The philosophy c/moral development. New York: Harper \& Row.

V. Upchurch, R. S., \& Ruhland, S. K. (1995). An Analysis of Ethical Work Climate and Leadership Relationship in Lodging Operations. Journal of Travel Research, 34(2), 3642.

VI. Reichers, A. E. \& Schneider, B. (1990). Organizational climate and culture. San Francisco, CA: Jossey-Bass.

VII. Schneider, B. (1975). ORGANIZATIONAL CLIMATES: AN ESSAY. Personnel Psychology, 28(4), 447-479.

VIII. Victor, B., \& Cullen, J. B. (1988). Ethical Climate Questionnaire--Modified. PsycTESTS Dataset. https://doi.org/10.1037/t35386-000

IX. Johnson, M. M., \& Gilligan, C. (1983). In a Different Voice: Psychological Theory and Women's Development. Contemporary Sociology, 12(4), 448.

X. Harrison, P. M., Haan, N., Aerts, E., \& Cooper, B. A. B. (1987). On Moral Grounds: The Search for Practical Morality. Journal for the Scientific Study of Religion, 26(2), 269.

XI. Peterson, D. K. (2002a). Deviant workplace behavior and the organization's ethical climate. Journal of Business and Psychology, 17(1), 47-61.

XII. Peterson, D. K. (2002b). The relationship between unethical behavior and the dimensions of the ethical climate questionnaire. Journal of Business Ethics, 41, 313-326.

XIII. Dumazert, J.-P., \& Plane, J.-M. (2012). Negative Deviant Behaviors in the Workplace: Causes and Impacts to Co-workers and Human Relations. Revue de Gestion Des Ressources Humaines, 86(4), 52. 
XIV. Morrison, R. L. (2008). Negative relationships in the workplace: Associations with organisational commitment, cohesion, job satisfaction and intention to turnover. Journal of Management \& Organization, 14(4), 330-344.

XV. Fu W, Deshpande SP (2014) The impact of caring climate, job satisfaction, and organizational commitment on job performance of Employees in a China's insurance company. J Bus Ethics 124(2):339-349

XVI. Creswell, J. W. (2003). Research design: qualitative, quantitative, and mixed method approaches. Sage Publications, Inc.

XVII. Clarke, V., \& Braun, V. (2014). Thematic Analysis. In Encyclopedia of Quality of Life and Well-Being Research (pp. 6626-6628).

XVIII. Harvey, L. (2014). Beyond member-checking: a dialogic approach to the research interview. International Journal of Research \& Method in Education, 38(1), 23-38.

XIX. Putranta, M. P., \& Kingshott, R. P. J. (2010). The Relationships Between Ethical Climates, Ethical Ideologies and Organisational Commitment Within Indonesian Higher Education Institutions. Journal of Academic Ethics, 9(1), 43-60.

XX. Parboteeah, K. P., Praveen Parboteeah, K., \& Kapp, E. A. (2007). Ethical Climates and Workplace Safety Behaviors: An Empirical Investigation. Journal of Business Ethics: JBE, 80(3), 515-529.

XXI. Kohlberg, L. (1984). The psychology of moral development: the nature and validity of moral stages. Harpercollins College Div.

XXII. Giacalone, R. A., \& Jurkiewicz, C. L. (2014). Handbook of Workplace Spirituality and Organizational Performance. Routledge.

XXIII. Upchurch, R. S., \& Ruhland, S. K. (1995). An Analysis of Ethical Work Climate and Leadership Relationship in Lodging Operations. Journal of Travel Research, 34(2), 3642.

XXIV. Simha, A., \& Stachowicz-Stanusch, A. (2015). The effects of ethical climates on trust in supervisor and trust in organization in a Polish context. Management Decision, 53(1), 24-39.

XXV. Ferrell, O. C., Fraedrich, J., \& Ferrell, L. (2010). Business Ethics and Policy: Ethical Decision Making and Cases.

XXVI. Lewin, L., \& Lavery, D. (1991). Self-Interest and Public Interest. In Self-Interest and Public Interest in Western Politics (pp. 1-28).

XXVII. Shaw, W. H. (2002). Business Ethics. Thomson Learning.

XXVIII. Arnold, D. G., Beauchamp, T. L., Bowie, N. E., \& Bowie, N. L. (2013). Ethical Theory and Business: Pearson New International Edition. Pearson.

XXIX. Elçi, M., \& Alpkan, L. (2008). The Impact of Perceived Organizational Ethical Climate on Work Satisfaction. Journal of Business Ethics: JBE, 84(3), 297-311.

XXX. Yener, M., Yaldıran, M., \& Ergun, S. (2012). The Effect of Ethical Climate on Work Engagement. Procedia - Social and Behavioral Sciences, 58, 724-733.

XXXI. Karatepe, O. (2013). Inking Perceived Ethical Climate to Performance Outcomes: The Mediating Role of Job Embeddedness. Economic Research-Ekonomska Istraživanja, 26(4), 77-90. 